\title{
Approaches to "Xenophobia" interventions in Africa: Common narratives through community radio in South Africa
}

\author{
TMUSWEDE ${ }^{l}$
}

\begin{abstract}
The article explores the prospects of community radio programming in providing organic interventions against xenophobia in South Africa. In the context of mounting migrationrelated complexities globally, the media have increasingly become a fundamental communication infrastructure through which citizens come to understand realities that affect their daily lives. This observation is particularly applicable to the majority of South Africans who currently face multiple socio-economic challenges, cited as the "ignition spark" to recent xenophobic attacks on immigrants in the media. Numerous public institutions including government and civic society have used mainstream media to champion condemnations of these attacks, however through optimistic top-down projections such as national electronic and print publications, with limited success. Although the latter forms of communication do reach large audiences, they lack heterogeneous appeal and are usually carriers of dominant discourses embedded in structural biases that are slanted towards the elite. This approach often marginalises the lower stratum of the population who usually bear the brunt of the xenophobic scourge as either perpetrators or victims thereof. The article uses participatory communication models to explicate how, as a typical product and reflection of the dynamics of the communities it serves, community radio could be used to promote a grassroots common narrative context for reflective anti-xenophobia communication discourse. The article concludes that, as part of the broader multimedia intervention strategy, community radio can provide an effective local perspective to the anti-xenophobia discourse through sustainable mainstreaming of migration issues in its programming.
\end{abstract}

Keywords: community radio, xenophobia, migration, participatory communication models, mainstreaming

\section{Introduction}

The high levels of xenophobia and anti-immigrant sentiments in southern Africa are largely a product of (mis)information about foreigners from secondary sources including the media (McDonald \& Jacobs, 2005). The latter have a profound responsibility to challenge and transform societal perceptions held about foreign nationals. In certain instances, the media are the only contact some South Africans have with foreign migrants and as such, they have an indirect influence on social construction of xenophobic attitudes. Since the fateful xenophobic attacks towards foreign nationals in South Africa in 2008, the mass media have somewhat been used by both government and civil society as part of a broad public intervention strategy to stop the scourge and to encourage African solidarity. Nevertheless, widespread coverage of these events primarily on mainstream, large commercial and national

1 Department of Languages \& Communication, University of Limpopo, Private Bag X1106, Sovenga, 0727, South Africa, E-mail: thabiso.muswede@ul.ac.za

Td The Journal for Transdisciplinary Research in Southern Africa, 11(4), December 2015, Special edition, 
formats such as television, radio and newspapers often failed to effectively address these attitudes (Lerner, Roberts \& Matlala, 2009). Instead, xenophobic tendencies have continued unabated, albeit in sporadic fashions, attracting less press reportage and government attention until the recent xenophobic outburst in April 2015, which left at least seven people dead, displacing thousands.

Notably, coverage of these issues in community media remains largely unexplored; yet, it is local communities that feel the effects of continuing discriminatory tensions and the impact of migration most keenly (Lerner et al., 2009: 20). This is supported by findings in a study by the Institute for Democracy in Southern Africa (IDASA), which holds that xenophobic violence in May 2008 appeared to be a result of "decentralised community organising; that it was focused in informal areas; and, that strong organisational structures, particularly local government institutions, in some cases, served to mitigate the violence" (IDASA, 2008: 8). Moreover, Misago (2009) also argued that "strong community leadership" served to prevent further xenophobic violence against foreign nationals. Hence, this article argues that, if we acknowledge that xenophobic violence and discrimination against foreigners happens largely at the community level, then the adoption of top-down extensive exogenous national interventions without emphasis on community approaches is questionable, if not irrelevant.

Moreover, generalised approaches fail to reach the target population groups who are in the lower economic stratum because they lack heterogeneous appeal to these target audiences, organisationally. Often, these channels are carriers of dominant discourses embedded in structural bias and slanted towards the elite (Mundy \& Compton, 1991). This is evidenced by their regular use of formalist news angles and choice of media analysts. The latter are often associated with big state-sponsored or corporate institutions, and they tend to interpret xenophobic events from a superficial and remote perspective that hardly resonates with the realities of people on the ground. More often than not, the illiterate and semi-literate are marginalised due to the highly pitched discourses that usually attribute xenophobia to "deeper political agendas ... rather than to bread and butter issues of poverty" (IDASA, 2008: 8). On numerous instances, xenophobic violence has often been associated with criminality, an approach that ignores the realities and further frustrates the "players".

On the contrary, community broadcasting in South Africa boasts at least 204 radio stations with a listenership of over 8.3 million across the length and breadth of the country; and, it is recognised as a critical component of grassroots development (Panther, 2014). More importantly, the sector serves largely poor communities faced with high unemployment and lack of access to basic infrastructure and services (Muswede, 2009), arguably a breeding ground for xenophobia due to competition for scarce resources among residents. In this view, the article explores how a developmental and participatory community radio programming that is differentiated from other forms of mass media can be used as a sustainable platform to provide organic interventions through the promotion of anti-xenophobia social dialogue. It interrogates how proximity to its target audiences gives community radio an additional impetus to giving marginalised communities a voice.

\section{Development communication models}

\section{Development communication challenge}

Despite having numerous definitions, the concept of development has key aspects upon which it is premised. It is also on the basis of these aspects that development communication 
should be defined and interpreted in order for it to impact on people's lives. Todaro (1994) identified three elements that entail the process of development as:

- Improving the quality of all human lives by raising people's living standards through economic growth;

- Improving the self-esteem of people by establishing the relevant social, economic and political systems and institutions that will promote human dignity and respect; and,

- Increasing people's freedom to choose and broaden their range of choices

As a rainbow nation, the post-1994 South African society has a diverse population outlook characterised by a dramatic communication environment, amid developmental challenges. This makes it important to acknowledge that any interventionist communication endeavour to deal with complex social milieu such as poverty, crime and xenophobia among citizens, will be difficult to handle. Despite the information revolution that has created the virtuous global village, stark reality is that in some parts of the developing world, including South Africa, many people still do not have adequate access to mainstream media information, let alone the internet. They have to combat the challenges of lack of basic services, unemployment and poverty in the context of complex migration problems inter alia, without the assistance of new technologies. As such, the suitability of the means of communication in determining the success of any corrective campaign in South Africa, will have to be informed by a needs analysis and evaluation mechanisms within the communication process (Barker, 2001). This is important in order to adopt the relevant social, economic and political systems that will promote human dignity and respect.

For several decades, the developing nations have built their systems on a colonial legacy that made little provision for the unique conditions of third world countries. These have been characterised by the absence of communication infrastructure, professional skills, economic means of production and cultural resources. Compounding this predicament is the high level of illiteracy and the diversity of languages used in these countries (Roelofse, 1997: 56). In addition, the dependency syndrome has continued in the post-colonial era in the form of neo-colonialism and cultural imperialism. To address this deficit, developing countries have advocated for the positive use of the media to promote national development, autonomy and cultural identity among other issues (McQuail, 1987: 119). This model lies within the development strategy which does not merely suggest inclusiveness of, but provides a delivery mechanism that largely arises from the recipients of these media initiatives. Hence, central to this approach are such tenets as participation, cultural identity, community empowerment and dialogical communication (Banda, 2003). In South Africa, this approach was realised through the development of a media regulatory framework that encapsulates media pluralism and diversity such as the three tier broadcasting system that includes community broadcasting (Independent Communications Authority of South Africa, 2000).

\section{Community development approach}

Community development practice has generally been predicated on theoretical propositions that maintain that people have the right to participate in decisions which have an effect upon their well-being (Cook, 1994: 14). This submits a conceptual framework that presents a logical basis for and general guides to the use of an open system or democratic structuring. It calls for the application of a holistic approach in efforts to stimulate the building of capacities, and to improve the performance of community systems (Cook, 1994: 20). The theory establishes an orientation toward community systems and human behaviours that are 
considered relevant in and for particular types of social organisations. It does not purport to give answers to the basic questions of what, why, or how this should happen for every community system. However, it does provide a conceptual platform or grounding for the building of community and provides theoretical bases by which to guide and assess interventions in each particular system (Cook, 1994: 10).

Development goes beyond economic growth and technological advancement, and must be seen as a process of expanding the real freedoms that people enjoy; and, this has found an ideal expression through community media (Sen, 2000). Current development theory places people central to development, believing that the opportunity to participate in development projects will determine the achievement of outcomes that people value, and have reason to value (Roelofse, 1997: 57; Bell \& Morse, 1999: 65-7). It also places change in both the context of individuals and the larger context of social structures. In Sen's (2000) view, development in local radio should therefore be seen in the context of the removal of tyranny, poverty, inequality and intolerance in favour of building community service institutions and economies. Instead of using media and communication as a one-way means of persuasion and of disseminating information from the developed to the undeveloped community, the media should be seen as tools or facilitators of development, and as vehicles for community selfexpression and empowerment (Roelofse, 1997: 57). In this context, development communication should be seen as a process that must involve both the transmission of messages about development issues, and empowerment of the disadvantaged to have a greater control of their social, political and economic institutions. In this view, development radio, community radio in particular, acts both as a catalyst for and a facilitator of change for communities to participate in reconstruction, development and democracy (Mtimde, 2000: 6), a favourable platform for locating the anti-xenophobia dialogue.

\section{Democratic participatory communication model}

The democratic participatory communication model comprises most of the ideal features compatible with community sound broadcasting, particularly its local focus. Second, the approach represents a flexible theoretical framework within which a variety of community media projects can easily and justifiably be located (Banda, 2003). The model highlights the importance of cultural identity from the perspective of local players and advances the need for the democratisation of local people at all levels. The communication process is tailored around formulation of meanings based on the social relational patterns and social institutions that are the result of and are determined by the communication process (Banda, 2003). This demonstrates a shift from the positivist-instrumentalist paradigm towards "another development" model that embraces the notion that communication should be characterised by multiplicity, smallness of scale, locality, de-institutionalisation, interchange of senderreceiver roles and horizontality of communication links at all levels of society (McQuail, 1987: 97; Melkote, 1991: 234).

The above argument is premised on the Freirian pedagogy of dialogic communication where interactive participation becomes a process of conscientisation in which dialogue is inherently audience-driven and conscious of the social structure (Freire, 1996; Banda, 2003). This is in contrast to the traditional pedagogical communication systems which perceived audiences as passive and gullible recipients of the world view of the elite class. Subsequently, this uncritical ingestion of elite-framed content made audiences to perceive their lives in terms of the latter's frame of reality. It is within this context that Freire then posited a contemporary dialogical pedagogy in which the receiver would be emancipated from the mental inertia of elitist 
programming as it were. Thus, participatory communication assists the audiences to evolve out of the ideological "cocoon" into which they were immersed by elites and then autonomously perceived the realities of their existence (Banda, 2003: 121). As such, instead of superimposing a universal structural change mechanism based on the dominant paradigm, community media are a typical concept based on priorities that are more contextual to the needs and challenges of specific communities (Banda, 2003).

The democratic participant model was developed in reaction to existing paradigms such as the normative theories which rarely took into account the development of new media and the rise of large media organisations (Fourie, 2001: 274). It is primarily a reaction to the trends towards commercialisation and monopoly formulation in privately owned mass media and towards centralisation and bureaucratisation in public broadcasting (Roelofse, 1997: 58). The democratic participant model advocates for the promotion of media development towards the direct and active participation of communities in publications and narrowcasting as opposed to broadcasting. The participant media theory is characterised by the establishment of more local and community radio stations with more talk radio programmes, phone-in programmes, interactive television systems and digital villages (Fourie, 2001: 274; McQuail, 1987: 119121 ), to empower the ordinary citizen whose voice has been marginalised for many decades.

\section{Overview of community Radio in South Africa}

\section{Background and operational context}

In Girard (2007)'s view, community radio basically refers to the radio in the community, for the community, about the community and by the community. It is characterised by wide participation from regular community members with respect to management and production of programmes. The involvement of community members distinguishes it from the dominant commercial media that are operated for profit, propaganda, power, politics, privilege, et cetera. Over and above these conditions, mainstream media serve the people or the public as a token gesture mainly to justify their existence in the government bureaucratic licensing procedures. To the contrary, community stations are collectively operated by the community, dedicated to development, education and people empowerment. They operate to achieve the principles of democracy and community development through community participation (Jordan, 2006: 1).

Community radio belongs to the third layer of broadcasting in South Africa. It is basically characterised by community ownership and control usually through a trust, foundation or association with the goal of serving the interests of particular communities (Fraser \& Estrada, 2001: 3). It is a non-profit entity which operates for non-profitable purposes. The stations' success is dependent on encouraging community membership and stakeholders who actively participate in its operations including the selection and creation of programmes. Funding of community radio stations usually comes from various sources such as donations, grants, membership fees or sale of advertising time or a combination of all these methods (Wigston, 2001: 429). A clear distinction between the community radio sector and private or public radio is the element of participation by listeners at all levels of the station. This involves the inclusion of community members in the board, management and programming structures of the station. Hence, community radio's primary object is to empower those who were previously disempowered in order to enable them to participate in determining their own destiny through community systems (Lloyd, 2000: 8). 


\section{Goals of community radio}

The concept of development entails the involvement of the people in their own development as reflected in their participation in radio programming, ownership and control (Simmering \& Fairbairn, 2007: 10). Accordingly, members of the community take development of the community into their hands by assuming various roles in the running of the station as volunteers, presenters, developers of programme content and other station management responsibilities. These attributes of community radio broadcasting make the sector to be viewed as a vehicle for the development of rural communities where most of these stations are located (Mmusi, 2005: 102). More importantly, the community development features of community radio make it a culturally appropriate horizontal communication process through which community issues such as "ubuntu" can be addressed through public dialogue.

Community radio aims to serve target communities with information, education and entertainment as a pragmatic tool for community development by embracing active community participation. Central to community radio is the ability to ensure that stations remain available to community residents to allow them to participate in the programmes, express their needs or discuss their issues of interest. Stations must be accessible to members to enable them productive access and benefit. Furthermore, the station must be acceptable and accountable to its target market by catering for the listeners' diverse needs and respecting the languages, traditions, beliefs and cultures of the respective communities. Affordability to the community members serves to allow listeners the possibility to contribute what they can afford to help sustain the daily running of the station as a community project (Open Society Foundation, 1999: 10; Fairbairn, 2000: 7).

\section{Interactive programming}

As a two-way communication devise, community radio thrives on active participation from both the radio personnel and its audiences in order to add value to the community. It pays special attention to soliciting messages from listeners through simple interactive means such as ordinary letters, phone-in shows, electronic mail, open broadcasts, public meetings et cetera. This provides an instant feedback mechanism which is often absent in other forms of media such as print, because daily newspapers have a minimum turnaround time of one day. As a result, until cheap television production, videophones, and broadband internet are universally accessible, community radio still remains by far the most appropriate medium with immediate feedback for poor communities, particularly rural people. As a success factor, community radio marketing encourages and facilitates interactive links between programme producers and audiences through local-oriented interactive activities, engendering a relevant audience-driven programming that better meets the consumers' needs (List, 2002: 54).

Community radio programmes can be tailored to serve specific groups of interest such as women, youth or linguistic and cultural minorities. In certain instances, a special slant on news, entertainment and education can be designed specifically to support social change and development in the community. The approach often encourages local creative talent and fosters local traditions while providing entertainment, education and development programmes for the benefit of listeners. This kind of community radio programming is reflective of a collective local expression of issues, often neglected by mainstream media, that constitutes the backbone and unique aspect of existence within localities (Fraser \& Estrada, 2001: 18; Girard, 2007: 2). Community radio, therefore, evidently addresses the glaring inadequacies and knowledge gaps in broad mass media interventions that often result from 
disregard of specific groups of people with unique programming preferences. Furthermore, it is a prompt response to the need for more focused strategies that can address group-specific needs.

\section{Social capital through community radio}

Community radio's founding principles are engendered to promote community development through a unique participatory decision making process to create social capital. Social capital is the ability of people to work together for common purposes in groups, organisations and workplaces (Fukuyama, 1995: 6) to enhance social collaboration that creates the possibility for community development. This allows the community to uphold decisions that should be made by those most directly affected by their outcomes in order to meet their group needs (Vuuren, 2001). Based on the social themes of trust and accountability, honest and cooperative behaviour, community radio operates on the basis of shared norms and values generally understood as unauthored formula for determining appropriate behaviour. It draws from a philosophy of the commons where individuals are not motivated by utilitarian interests in pursuit of pleasure but by collective social and individual goals (Onyx \& Bullen, 1997).

Social capital thrives on participatory networks with mutual relationships between individuals and groups regardless of their geographic communities. Community radio stations achieve this partially through voluntarism, community outreach programmes and annual general meetings where Board members are elected in the common interest. The regulatory framework for the sector requires audiences to be a pro-active citizenry that is willing to contribute to community development with a sense of both personal and collective capacities to produce desired outcomes. Although not all non-profit organisations are conducive to creation of social capital, due to their horizontal, voluntary operational and governance structures, community radio stations are capable of generating sustained social capital among their target audiences (Onyx \& Bullen, 1997).

\section{Towards an integrated strategy for mainstreaming xenophobia}

Based on the theoretical underpinnings and the tenets of community development and participatory communication, abundant possibilities exist towards the formulation of an integrated strategy for mainstreaming migration issues, including xenophobia, through community radio programming. This entails taking into account migration concerns in the organisational processes of community radio to contribute towards the transformation of xenophobic attitudes. In this discussion, reference is made to institutional documents of community radio as key elements to strategically operationalise both editorial and programming activities in the mainstreaming process. Hence, the study proposes that, through the "demystified" informal broadcasting environment provided by community radio, programmers can mainstream migration issues through the means discussed hereunder.

\section{Social inclusivity to address negative stereotypes}

Stereotypical representation of immigrants including use of derogatory terms such as makwerekwere, aliens, foreigners or illegals is often a challenge in the media in general (Nyamnjoh, 2010), because it has the potential to present them as threats to locals. This has often been the source of hatred leading to the exclusion of immigrants as their "large-scale" migration is perceived to put pressure on the existing scarce resources in the host countries. Therefore, community radio programmes could be used to deconstruct these stereotypes by 
promoting a fresh alternate discourse about migrants with a deliberate emphasis on the benefits of migration. Programmes could be tailored to explain the contributions of migrants to the local economy where they undertake hazardous and dangerous unwanted tasks (Ramakrishnan \& Arora, 2015) that most South Africans usually do not want to perform. These highlights should be mainstreamed, in order to portray how immigrants have historically been and continue to be the backbone of the infrastructural development of South African cities by shouldering the bulk of the construction and labour tasks (Ramakrishnan \& Arora, 2015). Positive representation of migrants would assist to dispel common myths and stereotypes, especially those that associate them with stealing jobs, criminality, witchcraft, dreadful diseases and so on, as a concerted effort towards encouraging social integration.

\section{Design of content and series that address migration issues}

Community radio programming is inherently community-driven, hence the mainstreaming strategy should begin with the application of development communication methods that inform programme design based on community needs analysis. In South Africa, community radio, as it is commonly known, is governed by the Broadcasting Act (1999), ICASA (2000) and the Electronic Communications Act No 36 of 2005, as policy guidelines regarding content development and how the sector should relate to target communities. Although these regulations may vary based on context, there are commonalities in the application of these guidelines on content development, globally (Ramakrishnan \& Arora, 2015). In addition to broadcasting in local languages and/or dialects, community radio ensures that its programmes do not cover content that is contemptuous of any religious communities nor promote disharmony among groups or perpetuates hatred against any person or group on the basis of ethnicity, nationality, race, gender, sexual orientation or any form of disability (Ramakrishnan \& Arora, 2015). In this context, content design could be tailored to include the concerns of immigrants or foreign nationals. This deliverable could be reinforced by incorporating migration matters into policy statements which, in turn, inform or govern programme scheduling and other operational activities of the stations. Humanity and/or faith-based themes that resonate with the African philosophy of Ubuntu could be infused into various projects such as outreach events, special day commemorations and drama storylines. Therefore, the article argues that inclusion of these fundamental elements could underpin the xenophobia discourse on community radio with the main emphasis placed on coverage of issues relating to the treatment of immigrants and other vulnerable groups within the broader community.

\section{Development of participatory and representative content}

The mainstreaming of migration issues should further be based on the development of participatory and representative content. This should be premised on an all-encompassing, transparent and participatory programming process that depicts a representative community outlook irrespective of social hierarchies. This will ensure that issues and concerns of all members in the community are reflected in the programmes, made possible through the input of volunteers who are best placed to understand the concerns of the locals and have the ability to articulate them effectively in the familiar language of target audiences. Participation in such programmes can also take the form of expert interview clips, vox pops and the phone-in programme where individual callers air their views or concerns. This approach could help to demystify stereotypes about the presence, activities and circumstances around foreign nationals. Stations could also feature migration issues on their weekly editorial reviews featuring local commentators as news sources to explore local news angles to xenophobia.

$T d, 10(4)$, December 2015, Special edition, pp. 220-231. 


\section{Adoption of innovative programming formats}

As opposed to use of standard and professional formats adopted for mainstream broadcasting that are usually associated with the elite class dimension, community radio programing incorporates elements that enable community members to openly talk (talk shows) about their issues and concerns, without standard gatekeeping procedures. The programmes practically advance the articulation of public opinion, highlight collective grievances and promote the transference of shared knowledge which top-down communication structures often systematically stifle through bureaucratic capping (Hadland, 2010). This approach fits in well within the sphere of empowering communities that are "voice-poor, and bereft of opportunities to openly express themselves" (Ramakrishnan \& Arora, 2015) as an alternative to violence resulting from the public's anger and frustrations over bread and butter issues.

Examples of innovative formats may involve use of storytelling formats and drama which have traditionally been well received as part of generic radio programming. Drama as a popular genre on community radio takes different forms such as monologues, multi-part drama (episodic) and docu-drama series. Used in combination with other formats such as live programme phone-ins, off-line voice messaging, magazine show or feature and social media input, these formats can invoke social mobilisation and create linkages between those in the society's margins and citizens. Hence, these programming formats and other creative formats (depending on contexts) could be useful as both edutainment and infotainment leverages for awareness-building and promotion of empathetic gestures and solidarity towards immigrants.

\section{Collaborative content development partnerships}

In order to promote broad dialogue and understanding of migration issues among citizens, community radio programmers may work closely with stakeholders in the communities they serve. This can take the form of stakeholder's consultative meetings to share expertise and exchange information towards the creation of a "community of practice" forum. This has the potential to provide a creative brainstorming platform where innovative ways can be mooted through the involvement of local government officials and civil society including traditional leadership, corporate personnel, migrants, religious groups and professional bodies on how to address migration challenges. Broad community participation has the advantage of lending credibility and encouraging buy-in from members of the community and therefore can serve as part of an effective public awareness campaign strategy. Furthermore, due to financial challenges in community radio, participation by corporate stakeholders will assist in ensuring adequate commitment of sufficient resources towards the development of sustainable migration-sensitive programmes. Another alternate method may involve collaborative effort to create a common programme or content that will be used to provide a continuous stream of information (Ramakrishnan \& Arora, 2015), that can be shared with other radio stations on how to live together with African immigrants in South African communities.

\section{Guidelines for news reporting and programme packaging}

Operational guidelines in radio programming simply refer to documented internal principles or basic values that spell out procedures within which news and programmes are packaged and aired. Lessons on the formulation of reporting guidelines regarding xenophobia and migration issues could be learnt from the experiences of how the mainstream media in particular cover(ed) the HIV/AIDS scourge in the recent past (Swanepoel, Fourie \& Froneman, 2007). Due to the sensitivity of the subject and the vulnerability of migrant 
groups, editorial teams could be capacitated to comprehend the context and degree of thoughtfulness needed in reporting the situation of migrants. The significance of the guidelines lies in providing terms of reference for both management and newsroom staff, particularly as an induction document for new volunteers in the station who lack training on reporting about sensitive matters. Where necessary, additional clauses that encapsulates an ethical code will assist in guiding programming to ensure fair coverage of migration issues.

\section{Conclusion}

The article explored the prospects of community and participatory communication models to xenophobia interventionist dialogue in contrast to conventional approaches. It espouses theoretical propositions that support intervention designs that are conceived within community frameworks as opposed to top-down projections which are often external to target audiences and tend to marginalise the target addressee in the lower class dimension. This paradigm strives to address problems from the "collective interest" approach through the communal forms of decision-making and use of dialogic and democratic participatory processes. The community approach enhances and facilitates buy-in from local participants thereby rendering relevant and effective intervention programmes to target audiences. In view of the context within which xenophobic attacks occur, the article posits that the tenets of community development and democratic participatory communication serve as organic approaches to facilitate effective transformational dialogue on migration issues since they are situated within the community where the violence often happens, rather than in the elitist perspective. The article highlights community radio's potential in promoting grassroots narratives for reflective anti-xenophobia dialogue through programmes mainstreaming. Essentially, this involves the development of xenophobia-sensitive programming wherein all information, communication and institutional policies, programmes, training and capacity building purposefully take a constructive role to promote a better understanding of migration issues. This is intended to build a sustainable medium-long term campaign that incorporates immigration-related issues on the calendar and scheduling of community radio stations as opposed to the sporadic, event-based coverage of xenophobia often associated with the press such as mainstream newspapers. As such, community radio is an affordable low cost mechanism that can be adapted to local contexts to promote a local perspective to "xenophobia" interventions. In South Africa and elsewhere in the continent, the sector remains strategically positioned to influence positive attitudes by instilling African solidarity initiatives and championing the anti-xenophobic discourse through uniting people of diverse nationalities. Hence, there is a need for a systematic broad-based partnership to create a "community of practice" towards the design and implementation of sustainable mainstreaming of the anti-xenophobia discourse premised in the local sphere of governance.

\section{References}

Banda, F. 2003. Community Radio Broadcasting in Zambia: A policy perspective. An Unpublished Doctoral Thesis, UNISA, South Africa.

Barker, R. 2001. Communication with communities: A South African experience. Communicatio, 27(1): 3-14.

Bell, S. \& Morse, S. 1999. Sustainability Indicators: Measuring the Immeasurable. London: Earthscan.

Cook, J. B. 1994. Community Development Theory. Columbia: University of Missouri. 
Fairbairn, J. 2000. Community participation and sustainability in community radio. A paper presented at a Workshop on "Gender and Sustainability in Community Radio". GAP: Open Society Foundation-South Africa. pp.6-7.

Fraser, C. \& Estrada, S. R. 2001. Community Radio Handbook: Washington, DC: UNESCO.

Freire, P. 1996. Pedagogy of the Oppressed. In Jameson, K.P. \& Wilber, C.K. (eds.), The Political Economy of Development and Underdevelopment, $6^{\text {th }}$ edn. New York: McGrawHill.

Fukuyama, F. 1995. Trust. New York: The Free Press.

Girard, B. 2007. What is Community Media? http://man.comunica.org/archives/101 [Accessed: 08 May 2007].

Hadland, A. 2010. Shooting the messenger: Mediating the public and the role of the media in South Africa's Xenophobic Violence. Africa Development, 35(3): 119-143.

Institute for Democracy in Southern Africa (IDASA), 2008. Background Report on Recent Xenophobic Violence in Gauteng: Preliminary Investigation. Cape Town: Southern African Migration Project.

Jordan, A. 2006. Global Review of Community Radio. AMARC 9 World Conference.Saturday,11November.http://www.econewsafrica.org/default2.asp?active_ page_id=315\&id=26 [Accessed: 22 July 2007].

Lerner, A., Roberts, S. \& Matlala, C. 2009. Race and Migration in the Community Media: Local Stories, Common Stereotypes. Johannesburg: MDDA.

List, D. 2002. Participative Marketing for Local Radio. Wellington: Original Books.

Makhanya, M. 2015. Who Feels it, knows it. The City Press, 19 April 2015.

McDonald, D. \& Jacobs, S. 2005. Understanding Press Coverage of Cross-Border Migration in Southern Africa Since 2000. Cape Town: IDASA.

McQuail, D. 1987. Theories of Mass Communication, $2^{\text {nd }}$ edn. London: Sage.

Melkote, S. R. 1991. Communicating for Development in the Third World: Theory and Practice. London: Sage.

Misago, J. P. 2009. Towards Tolerance, Law and Dignity: Addressing Violence against Foreign Nationals in South Africa. Johannesburg: International Organisation for Migration.

Mmusi, S. O. 2005. The Impact of Community Broadcasting on Rural Development in South Africa. In Lesame, N.C. New Media: Technology and Policy in Developing Countries. Pretoria: Van Schaik Publishers.

Mtimde, L. 2000. Sustainability for Community Radio. A paper presented at the Namibia Community Broadcasting Conference. http://www.ourmedianet.org/members/Mtimde/Mtimde_CommRadiSustain.rtf [Accessed: 29 June 2007].

Mundy, P. \& Compton, L.J. 1991. Development Communication Report. Arlington: Clearing House. 
Muswede, T. 2009. Sustainability Challenges Facing Community Radio: A Comparative Study of Three Community Radio Stations in Limpopo Province. Unpublished MA Dissertation Submitted at the University of Limpopo, Sovenga.

Nyamnjoh, F.B. 2010. Racism, ethnicity and the media in Africa: Reflections inspired by studies of xenophobia in Cameroon and South Africa. Africa Spectrum, 45(1): 57-93.

Onxy, J. \& Bullen, P. 1997. Measuring Social Capital in Five Communities in NSW: An Analysis. CACOM Working Paper No 41. Sydney: CACOM University of Technology.

Open Society Foundation, 1999. Community Radio Manual. Cape Town: OSF-SA.

Pather, J. 2014. Community Radio: A View of the Landscape after Twenty Years. In Seery, U. \& Seeber, M. (eds.), Media Landscape 2014: Celebrating 20 Years of South Africa's Media. Boksburg: Government Printers, pp.132-145.

Ramakrishnana, N. \& Arora, V. 2015. Internal Migration: A Manual for Community Radio Stations. New Delhi: UNESCO House.

Roelosfe, K. 1997. Press theories. In Oosthuizen, L.M. (ed.), Journalism, Press and Radio Studies. Kenwyn: Juta, pp.30-60.

Sen, A. 2000. Development as Freedom. New York: Anchor Books.

Siemering, B. \& Fairbairn, J. 2007. Community Radio Guidebook on Sustainability: Developing Radio Partners. http://www.developingradiopartners.org/downloads/Lo\%20Res\%20Guidebook.pdf [Accessed: 22 July 2007].

Swanepoel, T., Fourie, L.M. \& Froneman, J.D. 2007. HIV/Aids reporting in three South African newspapers. Communicare, 26(1): 74-91.

Tarafdar, M. \& Khan, N.I. 2008. Community Radio and Education for All: A Bangladesh Perspective. Bangladesh: Bangladesh Open University.

Todaro, M. 1994. Economic Development, $5^{\text {th }}$ edn. New York: Longman.

Van Nuuren, K. 2001. Beyond the Studio: A Case Study of Community Radio and Social Capital. Queensland: Australian Community Broadcasting Series.

Wigston, D. 2001. Radio Production. In Fourie, P.J. (ed.), Media Studies: Content, Audiences and Production. Lansdowne: Juta Education. 